\title{
Factors associated with health-related quality of life in renal transplant recipients: results of a national survey in France
}

Stéphanie Gentile ${ }^{1,2^{*}}$, Davy Beauger ${ }^{1}$, Elodie Speyer ${ }^{5,6}$, Elisabeth Jouve ${ }^{2}$, Bertrand Dussol ${ }^{3}$, Christian Jacquelinet $^{4}$ and Serge Briançon ${ }^{5,6}$

\begin{abstract}
Background: This study aims to identify factors associated with health related quality of life (HRQOL) through a comprehensive analysis of sociodemographic and clinical variables among a representative sample size of renal transplant recipients (RTR) in France.

Methods: A cross-sectional multicenter study was carried out in 2008. All RTR over 18 years old with a functioning graft for at least one year were included. Data included socio-demographic, health status, and treatment characteristics. To evaluate HRQOL, the Short Form-36 Health Survey (SF-36) and a HRQOL instrument for RTR (ReTransQol) were administered. Multivariate linear regression models were performed.

Results: A total of 1061 RTR were included, with a return rate of $72.5 \%$. The variance explained in regression models of SF-36 ranges from 20\% to 40\% and from 9\% to 33\% for ReTransQol.

The variables which decreased scores of both $\mathrm{HRQOL}$ questionnaires were: females, unemployment, lower education, living alone, high BMI, diabetes, recent critical illness and hospitalization, non-compliance, a long duration of dialysis and treatment side effects.

Specific variables which decreased ReTransQol scores were dismissal and a recent surgery on the graft. These which decreased SF36 scores were being old and a recent infectious disease.

The variables the most predictors of worse HRQOL were: side effects, infectious disease, recent hospitalization and female gender.

Conclusions: The originality of our study's findings was that novel variables, particularly treatment side effects and unemployment, have a negative effect on quality of life of RTR. The French Biomedicine Agency and the National Health Institute for Public Health Surveillance conduct specific actions for professional reintegration and therapeutic education programs in the national plan to improve the HRQOL of people living with chronic diseases.
\end{abstract}

Keywords: Associated factors, Cross-sectional multicenter study, Quality of life, Renal transplant recipient, ReTransQol, SF-36

\footnotetext{
* Correspondence: stephanie.gentile@ap-hm.fr

'Laboratoire de Santé Publique, Faculté de Médecine, Université Aix-Marseille,

Marseille EA 3279, France

${ }^{2}$ Service Santé Publique et Information Médicale, CHU Marseille, Marseille,

France

Full list of author information is available at the end of the article
} 


\section{Introduction}

In public health and in medicine, the concept of healthrelated quality of life (HRQOL) is defined as an individual's perception of their position in life in the context of the culture and value systems in which they live and in relation to their goals, expectations, standards and concerns [1]. Physicians have often used HRQOL to measure the effects of chronic illness in their patients to better understand how an illness interferes with a person's day-to-day life $[2,3]$.

Although the HRQOL advantages of renal transplantation are well established [4-8], large differences of quality of life are often observed depending on specific transplant cohorts $[9,10]$. Life after renal transplantation presents negative aspects as well, such as a strict regimen of immunosuppressive drugs and its related side effects, frequent medical visits, infections, the uncertainty and anxiety concerning rejection episodes and potential loss of the graft [11-16]. Therefore, one of the most important issues for the future of transplantation is to more clearly specify the full range of personal, environmental and clinical factors that negatively influence HRQOL outcomes. A better understanding of the role of these factors is essential to develop interventions that maximize the HRQOL in the context of transplantation. The World Health Organization (WHO) prioritizes HRQOL improvement for people living with chronic diseases, End-stage renal disease patients were concerned by a specific WHO program [17]. In France, the August 9, 2004 public health law applied this priority, implementing a national plan to improve the HRQOL for people living with chronic diseases [18]. The French Biomedicine Agency and the National Institute for Public Health Surveillance have promoted studies to determine the level of HRQOL of end-stage renal disease patients in France, at the start of the national plan to improve the HRQOL of chronic disease patients $[19,20]$.

In France, dialysis patients are followed-up through the French Renal Epidemiology and Information Network (REIN) [21]. REIN began in 2002 to provide a tool for public health decision support, evaluation and research related to renal replacement therapies for endstage renal disease. It relies on a network of nephrologists, epidemiologists, patients and public health representatives coordinated regionally and nationally. Moreover, the renal transplant recipients (RTR) are registered in a transplant database (CRISTAL) managed by the French Biomedicine Agency [22], which collects social and medical data for all patients who receive an organ transplant. Both databases are updated regularly, and have been used as sources of data for the end-stage renal disease specific program to improve HRQOL.

Two separate studies planned as part of the "QUAVIREIN" (the French translation for Renal Quality of Life) multiregional projects have been performed in 8 of the 22 regions of France: one focusing on dialysis patients [23], and the second focusing on RTR when data were available for both populations. This study aims to identify factors associated with HRQOL through a comprehensive analysis of sociodemographic and clinical variables among a representative sample size of RTR in France.

\section{Materials and methods \\ Data sources}

A cross-sectional multicenter study was carried out in France between March 2007 and March 2008, in the eight regions of France participating in the REIN network in 2003: Auvergne, Bretagne, Champagne-Ardennes, Languedoc-Roussillon, Limousin, Lorraine, ProvenceAlpes-Côte d'Azur and Rhône-Alpes.

\section{Participants}

All RTR over 18 year of age with a functioning graft for at least one year were eligible. Multi-organ transplant patients before or simultaneously with their kidney transplant were excluded. RTR and their addresses were identified from the CRISTAL database. The sample was stratified by regions and age class, using the same sampling rate for each stratum. The sample size was calculated to detect a difference of 5 points in the Short Form-36 Health Survey (SF-36) HRQOL score considering a standard deviation of 20, assuming a two-sided level of $5 \%$ and $80 \%$ power. A maximum of four comparisons was scheduled. The sample size calculation was 1,000 patients. Considering a non-response rate of approximately $30 \%, 1,300$ questionnaires were sent in order to achieve 1,000 patients. We randomized an additional sample of 500 patients in case the response rate in some region or age class was not adequate. A total of 401 patients were not included: 155 were returned to sender, 3 deceased patients and 243 were lost to followup. Finally, 162 more questionnaires were sent to complete a lack of data in some age class, reaching a total of 1462 questionnaires sent in all 8 regions. The number of self-administrated questionnaires returned was 1061.

\section{Measures}

Data collection included demographic, socio-demographic, medical characteristics and HRQOL. All data were obtained directly from patients except their age, gender and nephropathy, which were obtained from the CRISTAL database.

\section{Socio-demographic characteristics}

Demographic variables assessed were gender, age, employment status (retirement, unemployment and working), education level (primary or less, secondary 1st 
stage and higher than secondary), living arrangement (living alone versus other status) and dismissal due to illness (when an employer did a procedure for dismissing a member of staff due to illness).

\section{Medical characteristics}

Medical measures were grouped into three domains related to kidney disease, health status, and treatment (i.e. drugs, side effects and compliance).

1. Kidney disease: etiology of end-stage renal failure, duration of dialysis, duration of transplantation and graft rejection episodes.

2. Health status: comorbidities (i.e. hypertension, Diabetes Mellitus), intercurrent health events during the last four weeks, critical illness, especially infectious disease, graft surgery, hospital admission, Body Mass Index (BMI), and smoking status.

3. Treatment: to collect the drug treatments, we established with nephrologists a selective list of the most commonly prescribed drugs using their generic names.

The patient could also add the medication if drugs were not included in the list. Therapeutics data were classified according to Anatomical Therapeutic and Chemical (ATC) classification [24].

4. Side effects: to collect treatment side effects, we used a list of 18 items identified by RTR [25]. The patient rated the importance on a 4-level Likert scale, ranging from "no discomfort" to "very significant discomfort".

Side effects were categorized into 5 domains according to the following classification:

1. General health: muscular weaknesses, general tiredness, pain, lower limb oedema, etc.

2. Mental Health: depression, anxiety, sleep disorders.

3. Body modification: facial changes, facial oedema, weight gain, hair loss, swollen gums, brittle skin, etc.

4. Sexual dysfunctional

5. Diarrhea

Three items explored compliance:

- Difficulty to respect the immunosuppressant schedule

- Modification of immunosuppressive therapy

- Modification of the dosage of treatments (other than immunosuppressive therapy drugs)

Patients who answered "yes" to one of these three items were categorized as non-compliant.

\section{Health-related quality of life}

SF-36 [26] and ReTransQol [27] were used to evaluate HRQOL.

The French version of the SF-36 is a generic instrument, with scores ranging from 0 (complete dissatisfaction) to 100 (full satisfaction) for eight domains: physical functioning (PF), role-physical (RP), bodily pain (BP), general health $(\mathrm{GH})$, vitality (VT), social functioning (SF), role-emotional (RE) and mental health $(\mathrm{MH})$. The correlated physical (PCS) and mental (MCS) summary components were computed following the standardized procedure provided by authors.

The ReTransQol is a specific instrument consisting of 45 items describing 5 dimensions: physical health $(\mathrm{PH})$, mental health $(\mathrm{MH})$, medical care and satisfaction $(\mathrm{MC})$, treatment (TRT) and fear of losing graft (FG). Each score ranges from 0 to 100 , and the higher the score, the better the perceived state of health [27].

\section{Data collection procedures}

All measurement instruments were sent to the patient's residence with a letter signed by the project coordinator. Patients returned the completed questionnaires via a pre-stamped envelope. Non-respondents were reminded by a second letter three weeks later and contacted by phone.

\section{Ethical aspects}

The study methodology was approved by the local Institutional Review Board (CCTIRS n'06-311) and the "Comité National Informatique et Liberté" (CNIL n906248), which ensures the confidentiality of all information collected.

\section{Statistical analysis}

Continuous variables were expressed as mean \pm standard deviation (SD) or range. Discrete variables were reported as frequency and percentage. Group comparisons were performed using analysis of variance (bivariate analysis). All factors with a p-value $<0.25$ were included as candidate variables in a multivariate analyses, according to the literature review.

Multivariate linear regression models (MLR) were used to estimate the relationship between HRQOL scores and socio-demographic, health status and treatment characteristics.

Multivariate analysis was summarized by the $\beta$ coefficients and their 95\% confidence interval and p-value. The R-squares were performed. The level of significance was set at a p-value $<0.05$ (factors presented). Statistical analysis was performed using $\mathrm{SAS}^{\oplus} 9.2$ system software.

\section{Results}

At the time of the survey, there were 5,991 patients present in the CRISTAL database living with a functional 
graft for at least one year in the 8 regions. Data referring to a total of 1061 patients were obtained from 1462 sampled, with a response rate of $72.5 \%$.

\section{Socio-demographic characteristics}

The mean age of patients was 55.2 years ( \pm 12.4 years) and $61.8 \%$ were male. Nearly $80 \%$ of RTR lived as a couple. Less than $40 \%$ of patients were employed at the time of the survey. Among unemployed RTR, half were retired. Patient characteristics are shown in Table 1.

\section{Medical characteristics}

Kidney disease: The mean time since transplantation was 8.5 years ( \pm 5.8 years, range $1-40$ ). A total of $23.5 \%$ of patients had at least one intercurrent health event in the past four weeks (Table 2). Among this sample, 11.1\% $(\mathrm{n}=111)$ had been hospitalized in the last four weeks, $4.7 \%(\mathrm{n}=47)$ had a critical illness, $13.7 \%(\mathrm{n}=123)$ had an infectious disease, $4 \%(n=42)$ had acute rejection episodes and $1.9 \%(\mathrm{n}=17)$ had a surgery on the graft in the last four weeks.

\section{Treatment}

Most patients (89.3\%) had two or three immunosuppressive drugs. Nearly $84 \%$ of patients had antihypertensives, 51.2\% had lipid lowering drugs and 9.5\% antidiabetic agents. Most of the patients (77.5\%) were compliant. Difficulty to respect the medication regimen was the main reason for non-compliance. The majority of patients (79\%) reported treatment side effects, particularly those related to body modification: $72.7 \%(\mathrm{n}=771)$. The mean number of side effects was $5.7 \pm 3.9$ (range 1-17) (Table 2).

\section{Health related quality of life}

Table 3 shows mean HRQOL scores and SD corresponding to the different dimensions of the SF-36 and ReTransQol questionnaires used.

Table 1 Socio-demographic characteristics

\begin{tabular}{lll}
\hline & $\mathbf{n}$ & $\%$ \\
\hline Male & 656 & $61.8 \%$ \\
Age, years (mean \pm SD) & $55.2 \pm 12.4$ & \\
Level of education & & \\
Primary or less & 260 & $25.8 \%$ \\
Secondary 1st stage (college \& high school) & 483 & $48 \%$ \\
Higher than secondary, 2nd stage or university & 264 & $26.2 \%$ \\
Living arrangement & & \\
Live alone & 186 & $19.2 \%$ \\
Employment status & & \\
Employed & 377 & $35.5 \%$ \\
Unemployed & 566 & $33.1 \%$ \\
Retired & 118 & $31.4 \%$ \\
\hline
\end{tabular}

\section{Variables included the final regression model for both HRQOL questionnaires}

In SF-36 and ReTransQol models of regression, at least 16 and 14 variables, respectively, were included to strengthen the model and obtain significant scores, with a good variance explanation for each dimension. Adjusted differences in the eight generic scales of SF-36 and in the five specific dimensions of ReTransQol using socio-demographic, medical and treatment variables are shown in Tables 4 and 5 . The variance explained in regression models for SF-36 ranges from 20\% to $40 \%$ (Table 4) and from 9\% to 33\% for ReTransQol (Table 5).

\section{Factors associated with a modification of HRQOL for SF-36}

The variables which were associated with lower SF-36 scores were: older age, female gender, unemployment, lower education, living alone, high BMI, diabetes, infectious disease, critical illness and hospitalization in the last 4 weeks, non-compliance, former smoker, a long duration of dialysis, side effects related to general health and mental health or body modification domains (Table 4).

The five variables which contributed most to a worse quality of life were: side effects related to general health and mental health domains, infectious disease, hospitalization in the last 4 weeks, and female gender (Figure 1). The "potentially modifiable" variables are in bold and the others are consider as "not likely modifiable" by intervention programs.

\section{Factors associated with a modification of HRQOL for retransQOL}

The following variables (Table 5) played a significant role in the reduction of HRQOL using the ReTransQol subscales: female gender, unemployment, dismissal, lower education, living alone, high BMI, side effects related to general health, mental health and body modification domains, infectious disease, critical illness, hospitalization in the last 4 weeks, non-compliant, a recent surgery on the graft and a long duration of dialysis (Figure 2).

The four variables which were associated with a lower quality of life are those associated to side effects related to mental health, body modifications and general health domains, and female gender.Discussion

We analyzed the factors associated with a lower quality of life in a representative sample of 1,061 renal transplant recipients from 8 regions of France. This study is the first report in France of HRQOL in kidney transplantation with such a large sample of patients.

The sociodemographic characteristics of our sample were similar to those reported in the literature [28-30]. Our sample is representative of general French RTR. Moreover, there are few studies with extensive observations carried out. In our literature review, few studies 
Table 2 Medical characteristics and treatments (compliance and side effects)

\begin{tabular}{llll}
\hline & & $\mathbf{n}$ & $\%$ \\
\hline $\begin{array}{l}\text { Medical } \\
\text { characteristics }\end{array}$ & Cadaveric donor transplantation & 1035 & $97.5 \%$ \\
& $\begin{array}{l}\text { Duration of transplantation, years } \\
\text { Patients with rejection since }\end{array}$ & 222 & $22.9 \%$ \\
& $\begin{array}{l}\text { renal transplant } \\
\text { Major causes of ESRD }\end{array}$ & & \\
& Chronic glomerular nephritis & 380 & $35.8 \%$ \\
& Interstitial nephropathy & 122 & $11.5 \%$ \\
& Hereditary nephropathy & 206 & $19.4 \%$ \\
& $\begin{array}{l}\text { Duration of dialysis, months } \\
\text { (mean } \pm \text { SD) }\end{array}$ & $31.3 \pm 37.2$ \\
& Intercurrent health events in & $\mathbf{2 4 5}$ & $\mathbf{2 3 . 2} \%$ \\
the last four weeks & & \\
& Hospitalization & 111 & $11.1 \%$ \\
& Critical illness & 47 & $4.7 \%$ \\
& Infectious disease & 123 & $13.7 \%$ \\
& Acute rejection episodes & 42 & $4.0 \%$ \\
& Graft surgery & 17 & $1.9 \%$ \\
& Comorbidities & &
\end{tabular}

Hypertension

$\mathrm{BMI}>30\left(\mathrm{~kg} / \mathrm{m}^{2}\right)$

Diabetes mellitus

Current smokers

Treatments, compliance and side
Side effects

Mean number of side effects per patient

Range

Mean number of drugs per patient

Immunosuppressive treatment

Calcineurin inhibitors

Corticosteroids

Antimetabolites

Proliferation inhibitors

Monotherapy

Bitherapy

Tritherapy

Other treatment

Antihypertensive drugs

Hypolipidemics

Antidiabetic agents

Non-compliant to treatment

Side effects related to:

General health

Mental health
Table 2 Medical characteristics and treatments (compliance and side effects) (Continued)

\begin{tabular}{lll} 
Body modification & 771 & $72.7 \%$ \\
Sexual disorders & 288 & $27.1 \%$ \\
Diarrhea & 216 & $20.4 \%$ \\
\hline
\end{tabular}

had a sample of over 1,000 patients [6,31,32]. Therefore, the substantial sample size, the response rate of $72.8 \%$, and multivariate analysis are strengths of the present study.

After an analyze of the literature review, the level of quality of life of our patients may be different [4] as well as similar [33-36], depending of the country of the study, the sample size, the medical care or the Public Health organization. In general, SF36 scores are slightly lower than those found in the literature, probably because of our big sample size of patients used compared with other studies.

Another strong point of the current study was the construction of a comprehensive multivariate model, including several sociodemographic, clinical and treatment variables in its adjusted analysis. The independent variables were selected based on a previous univariate analysis and from a literature review. The final regression models explained $32 \%$ of the physical (PCS) HRQOL variance and $23 \%$ of mental HRQOL variance (MCS). Previous studies describe that use of highly effective predictive regression models only explained between 3\% and $22 \%$ of HRQOL variance among chronic renal disease patients $[37,38]$.

Table 3 HRQOL scores

Dimensions

Means \pm SD

S F - 36

Physical Functioning- PF

$74.8 \pm 24.3$

Social Functioning- SF

$74.9 \pm 23.6$

Role Physical- RP

$64.4 \pm 41.3$

Role Emotional- RE

$68.8 \pm 41.3$

Mental Health

$65.5 \pm 18.7$

Vitality- VT

$53.3 \pm 19.3$

Bodily Pain- BP

$68.3 \pm 25.8$

General Heath- GH

$55.4 \pm 21$

Physical Component Summary- PCS

$45.8 \pm 9.7$

Mental Component Summary- MCS

$46.0 \pm 10.5$

ReTrans Qol

Physical Health - PH

$63.8 \pm 17.4$

Mental Health - MH

$72.6 \pm 16.7$

Medical Care - MC

$75.0 \pm 14.9$

Fear of losing the Graft - FG

$58.4 \pm 20.4$

Treatment - TRT 
Table 4 Final regression models (SF 36 domains)

\begin{tabular}{|c|c|c|c|c|}
\hline Dimensions & Variables & $\beta$ coeff. & $95 \% \mathrm{Cl}$ & $P$ values \\
\hline \multirow[t]{12}{*}{$\mathrm{PF}^{2}=0.31$} & Intercept & 95.4 & {$[91.1 ; 99.6]$} & $\overline{p<.0001}$ \\
\hline & Female & -4.7 & {$[-7.6 ;-1.7]$} & $p<0.0018$ \\
\hline & Age $\geq 75$ years & -23.3 & {$[-30.4 ;-16.2]$} & $p<.0001$ \\
\hline & Low educational (primary or less) & -7.5 & {$[-11.2 ;-3.8]$} & $p<.0001$ \\
\hline & Unemployment & -6.3 & {$[-9.4 ;-3.2]$} & $p<.0001$ \\
\hline & $\mathrm{BMI}>30\left(\mathrm{~kg} / \mathrm{m}^{2}\right)$ & -5.8 & {$[-10 ;-1.6]$} & $p<0.0065$ \\
\hline & Critical illness in the last 4 weeks & -8.0 & {$[-14.9 ;-1.1]$} & $p<0.0237$ \\
\hline & Diabetes & -5.6 & {$[-10.1 ;-1]$} & $p<0.0163$ \\
\hline & Side effects related to general health & -17.0 & {$[-20.9 ;-13.1]$} & $p<.0001$ \\
\hline & Side effects related to mental health & -6.8 & {$[-10.5 ;-3]$} & $p<0.0004$ \\
\hline & Recent surgery & -9.5 & {$[-24.9 ; 6]$} & $p<0.2283$ \\
\hline & Infectious disease in the last 4 weeks & -4.8 & {$[-9.1 ;-0.4]$} & $p<0.0311$ \\
\hline \multirow[t]{9}{*}{$\mathbf{R P} R^{2}=0.22$} & Intercept & 90.5 & {$[82.8 ; 98.1]$} & $p<.0001$ \\
\hline & Female & -6.9 & {$[-12.2 ;-1.6]$} & $p<0.0104$ \\
\hline & Age $\geq 75$ years & -20.1 & {$[-33.1 ;-7]$} & $p<0.0026$ \\
\hline & Low educational (primary or less) & -11.4 & {$[-18 ;-4.8]$} & $p<0.0007$ \\
\hline & Hospitalization in the last 4 weeks & -17.9 & {$[-27.1 ;-8.8]$} & $p<0.0001$ \\
\hline & Critical illness in the last 4 weeks & -31.5 & {$[-44.8 ;-18.1]$} & $p<.0001$ \\
\hline & Infectious disease in the last 4 weeks & -10.9 & {$[-19 ;-2.9]$} & $p<0.0080$ \\
\hline & Side effects related to general health & -21.5 & {$[-28.7 ;-14.3]$} & $\mathrm{p}<.0001$ \\
\hline & Side effects related to mental health & -16.0 & {$[-22.8 ;-9.1]$} & $p<.0001$ \\
\hline \multirow[t]{8}{*}{$\mathbf{B P}^{2}=0.23$} & Intercept & 85.3 & {$[80.6 ; 90]$} & $p<.0001$ \\
\hline & Female & -4.9 & {$[-8.1 ;-1.6]$} & $p<0.0035$ \\
\hline & Age $\geq 75$ years & -8.3 & {$[-16.1 ;-0.4]$} & $p<0.0402$ \\
\hline & Low educational (primary or less) & -6.5 & {$[-10.5 ;-2.5]$} & $p<0.0016$ \\
\hline & Infectious disease in the last 4 weeks & -9.1 & {$[-14 ;-4.3]$} & $p<0.0002$ \\
\hline & Side effects related to general health & -18.7 & {$[-23.2 ;-14.2]$} & $p<.0001$ \\
\hline & Side effects related to mental health & -9.7 & {$[-14 ;-5.4]$} & $p<.0001$ \\
\hline & Side effects related to body modification & -4.2 & {$[-7.7 ;-0.7]$} & $p<0.0193$ \\
\hline \multirow[t]{7}{*}{$\mathbf{M H} R^{2}=0.24$} & Intercept & 81.1 & {$[77.7 ; 84.6]$} & $p<.0001$ \\
\hline & Female & -5.6 & {$[-8 ;-3.3]$} & $p<.0001$ \\
\hline & Family status (living alone) & -4.6 & {$[-7.2 ;-1.9]$} & $p<0.0007$ \\
\hline & Duration of dialysis $>3$ years & -3.3 & {$[-5.8 ;-0.8]$} & $p<0.0087$ \\
\hline & Hospitalization in the last 4 weeks & -7.7 & {$[-11.4 ;-4]$} & $p<.0001$ \\
\hline & Side effects related to mental health & -16.5 & {$[-19.5 ;-13.5]$} & $p<.0001$ \\
\hline & Side effects related to body modification & -4.4 & {$[-6.9 ;-1.9]$} & $p<0.0005$ \\
\hline \multirow[t]{8}{*}{$\mathbf{R E} R^{2}=0.18$} & Intercept & 94.8 & {$[86.5 ; 103]$} & $p<.0001$ \\
\hline & Female & -6.4 & {$[-12 ;-0.8]$} & $p<0.0252$ \\
\hline & Low educational (primary or less) & -16.8 & {$[-24 ;-9.6]$} & $p<.0001$ \\
\hline & Age $\geq 75$ years & -11.1 & {$[-25.3 ; 3.2]$} & $p<0.1285$ \\
\hline & Family status (living alone) & -9.1 & {$[-15.3 ;-2.8]$} & $p<0.0045$ \\
\hline & Hospitalization in the last 4 weeks & -17.4 & {$[-26.7 ;-8.1]$} & $p<0.0003$ \\
\hline & Infectious disease in the last 4 weeks & -19.1 & {$[-27.6 ;-10.7]$} & $p<.0001$ \\
\hline & Side effects related to mental health & -25.0 & {$[-32 ;-18.1]$} & $p<.0001$ \\
\hline
\end{tabular}


Table 4 Final regression models (SF $\mathbf{3 6}$ domains) (Continued)

\begin{tabular}{|c|c|c|c|c|}
\hline \multirow[t]{8}{*}{ SF $R^{2}=0.25$} & Intercept & 90.8 & {$[86.8 ; 94.8]$} & $p<.0001$ \\
\hline & Female & -4.9 & {$[-7.6 ;-2.1]$} & $p<0.0006$ \\
\hline & Family status (living alone) & -4.6 & {$[-7.8 ;-1.5]$} & $p<0.0036$ \\
\hline & Hospitalization in the last 4 weeks & -11.8 & {$[-16.2 ;-7.3]$} & $p<.0001$ \\
\hline & Infectious disease in the last 4 weeks & -7.2 & {$[-11.5 ;-2.9]$} & $p<0.0011$ \\
\hline & Diabetes & -7.5 & {$[-11.5 ;-3.5]$} & $p<0.0002$ \\
\hline & Side effects related to general health & -11.3 & {$[-15 ;-7.6]$} & $p<.0001$ \\
\hline & Side effects related to mental health & -16.4 & {$[-20 ;-12.8]$} & $p<.0001$ \\
\hline \multirow[t]{6}{*}{ VT $R^{2}=0.22$} & Intercept & 62.8 & {$[59.6 ; 66.1]$} & $p<.0001$ \\
\hline & Female & -2.4 & {$[-4.6 ;-0.1]$} & $p<0.0366$ \\
\hline & Hospitalization in the last 4 weeks & -8.3 & {$[-11.8 ;-4.8]$} & $p<.0001$ \\
\hline & Side effects related to general health & -12 & {$[-15 ;-8.9]$} & $p<.0001$ \\
\hline & Side effects related to mental health & -11.7 & {$[-14.8 ;-8.7]$} & $p<.0001$ \\
\hline & Side effects related to body modification & -3.9 & {$[-6.3 ;-1.4]$} & $p<0.0020$ \\
\hline \multirow[t]{8}{*}{$\mathbf{G H} \mathrm{R}^{2}=0.18$} & Intercept & 63.8 & {$[62.1 ; 65.5]$} & $p<.0001$ \\
\hline & Hospitalization in the last 4 weeks & -6.1 & {$[-10.2 ;-2]$} & $p<0.0038$ \\
\hline & Critical illness in the last 4 weeks & -7.1 & {$[-13.5 ;-0.7]$} & $p<0.0305$ \\
\hline & Diabetes & -5.4 & {$[-9 ;-1.7]$} & $p<0.0038$ \\
\hline & Side effects related to general health & -11.6 & {$[-15.1 ;-8.1]$} & $p<.0001$ \\
\hline & Side effects related to mental health & -7.7 & {$[-11.1 ;-4.2]$} & $p<.0001$ \\
\hline & Side effects related to body modification & -5.6 & {$[-8.4 ;-2.9]$} & $\mathrm{p}<.0001$ \\
\hline & Non-compliant & -6.3 & {$[-9.2 ;-3.4]$} & $p<.0001$ \\
\hline \multirow[t]{8}{*}{ PCS $\left(R^{2}=0.28\right)$} & Intercept & 52.7 & {$[50.9 ; 54.5]$} & $p<.0001$ \\
\hline & Female & -1.7 & {$[-3 ;-0.4]$} & $p<0.0084$ \\
\hline & Age $\geq 75$ years & -7.7 & {$[-11 ;-4.3]$} & $p<.0001$ \\
\hline & Low educational (primary or less) & -3.3 & {$[-4.9 ;-1.7]$} & $p<.0001$ \\
\hline & Unemployment & -2.5 & {$[-3.8 ;-1.1]$} & $p<0.0003$ \\
\hline & Critical illness in the last 4 weeks & -5.7 & {$[-8.8 ;-2.6]$} & $p<0.0003$ \\
\hline & Infectious disease in the last 4 weeks & -3.2 & {$[-5.1 ;-1.3]$} & $p<0.0012$ \\
\hline & Side effects related to general health & -9.2 & {$[-10.8 ;-7.5]$} & $p<.0001$ \\
\hline \multirow[t]{6}{*}{ MCS $\left(R^{2}=0.22\right)$} & Intercept & 52.1 & {$[50.3 ; 54]$} & $p<.0001$ \\
\hline & Female & -1.7 & {$[-3 ;-0.4]$} & $p<0.0113$ \\
\hline & Family status (living alone) & -2.2 & {$[-3.7 ;-0.7]$} & $p<0.0039$ \\
\hline & Hospitalization in the last 4 weeks & -5.7 & {$[-7.8 ;-3.6]$} & $p<.0001$ \\
\hline & Side effects related to body modification & -2.5 & {$[-3.9 ;-1.1]$} & $p<0.0005$ \\
\hline & Side effects related to mental health & -9.3 & {$[-11 ;-7.7]$} & $p<.0001$ \\
\hline
\end{tabular}

As in other studies, we used a generic questionnaire of HRQOL associated with a specific one. We applied the generic instrument SF-36 Health Survey, the most used questionnaire for HRQOL analysis in RTR $[2,39,40]$ We also associated a disease-specific instrument validated for RTR in the French language: the ReTransQol [27].

In our study, quality of life scores were lower with all the socio-demographic and health status variables collected. The impact of socio-demographic variables is known for having a negative influence on HRQOL. These findings are in accordance with other studies: level of HRQOL significantly decreases with age [41], gender, living status and the educational level [34,42-44].

This study points out that unemployed patients have an extremely impaired HRQOL, especially for physical and mental dimensions, whatever the measurement instrument used $[43,45]$. This is why the French Biomedicine Agency and the National Health Institute for Public 
Table 5 Final regression models (ReTransQol domains)

\begin{tabular}{|c|c|c|c|c|}
\hline Dimensions & Variables & B coeff. & $95 \% \mathrm{Cl}$ & $P$ values \\
\hline \multirow[t]{11}{*}{$\mathrm{PH} \mathrm{R}^{2}=0.31$} & Intercept & 78.2 & {$[75.2 ; 81.2]$} & $p<.0001$ \\
\hline & Female & -2.5 & {$[-4.5 ;-0.5]$} & $p<0.0156$ \\
\hline & Low educational (primary or less) & -7.3 & {$[-9.6 ;-5.1]$} & $p<.0001$ \\
\hline & $\mathrm{BMI}>30\left(\mathrm{~kg} / \mathrm{m}^{2}\right)$ & -4.6 & {$[-7.4 ;-1.7]$} & $p<0.0021$ \\
\hline & Unemployment & -7.2 & {$[-9.4 ;-5.1]$} & $p<.0001$ \\
\hline & Duration of dialysis $>3$ years & -2.5 & {$[-4.7 ;-0.4]$} & $p<0.0226$ \\
\hline & Hospitalization in the last 4 weeks & -5.2 & {$[-8.6 ;-1.8]$} & $p<0.0029$ \\
\hline & Critical illness in the last 4 weeks & -6 & {$[-10.6 ;-1.4]$} & $p<0.0110$ \\
\hline & Side effects related to general health & -9.8 & {$[-12.5 ;-7]$} & $p<.0001$ \\
\hline & Side effects related to mental health & -6 & {$[-8.7 ;-3.3]$} & $p<.0001$ \\
\hline & Side effects related to body modification & -4.4 & {$[-6.6 ;-2.2]$} & $p<.0001$ \\
\hline \multirow[t]{10}{*}{$\mathbf{M H} \mathrm{R}^{2}=0.27$} & Intercept & 87 & {$[84.1 ; 89.9]$} & $p<.0001$ \\
\hline & Female & -4.1 & {$[-6.1 ;-2.2]$} & $p<.0001$ \\
\hline & Family status (living alone) & -8.1 & {$[-10.3 ;-5.8]$} & $p<.0001$ \\
\hline & Dismissal & -3.7 & {$[-6.7 ;-0.7]$} & $p<0.0152$ \\
\hline & Duration of dialysis $>3$ years & -3.9 & {$[-5.9 ;-1.8]$} & $p<0.0003$ \\
\hline & Hospitalization in the last 4 weeks & -5.1 & {$[-8.3 ;-2]$} & $p<0.0014$ \\
\hline & Recent surgery & -10.3 & {$[-18.2 ;-2.4]$} & $p<0.0107$ \\
\hline & Side effects related to general health & -6.4 & {$[-9.1 ;-3.7]$} & $p<.0001$ \\
\hline & Side effects related to mental health & -10.2 & {$[-12.8 ;-7.5]$} & $p<.0001$ \\
\hline & Side effects related to body modification & -3.7 & {$[-5.9 ;-1.6]$} & $p<0.0007$ \\
\hline \multirow[t]{6}{*}{$M C R^{2}=0.1$} & Intercept & 79.2 & {$[78 ; 80.5]$} & $p<.0001$ \\
\hline & Family status (living alone) & -3.8 & {$[-5.9 ;-1.7]$} & $p<0.0004$ \\
\hline & Dismissal & -3.1 & {$[-6 ;-0.2]$} & $p<0.0354$ \\
\hline & Side effects related to general health & -5.9 & {$[-8.4 ;-3.3]$} & $p<.0001$ \\
\hline & Side effects related to mental health & -3.6 & {$[-6.1 ;-1]$} & $p<0.0056$ \\
\hline & Side effects related to body modification & -2.9 & {$[-4.9 ;-0.8]$} & $p<0.0057$ \\
\hline \multirow[t]{6}{*}{$\operatorname{TR} R^{2}=0.31$} & Intercept & 77.4 & {$[76.4 ; 78.4]$} & $p<.0001$ \\
\hline & $\mathrm{BMI}>30\left(\mathrm{~kg} / \mathrm{m}^{2}\right)$ & -3.2 & {$[-5.3 ;-1.1]$} & $p<0.0030$ \\
\hline & Non-compliant & -4.4 & {$[-6.1 ;-2.7]$} & $p<.0001$ \\
\hline & Side effects related to general health & -9.5 & {$[-11.5 ;-7.5]$} & $p<.0001$ \\
\hline & Side effects related to mental health & -6.8 & {$[-8.8 ;-4.8]$} & $p<.0001$ \\
\hline & Side effects related to body modification & -7.5 & {$[-9.1 ;-5.9]$} & $p<.0001$ \\
\hline \multirow[t]{4}{*}{$\mathbf{F G ~} R^{2}=0.1$} & Intercept & 66.5 & {$[62.3 ; 70.7]$} & $p<.0001$ \\
\hline & Female & -3 & {$[-5.8 ;-0.1]$} & $p<0.0409$ \\
\hline & Side effects related to mental health & -11.4 & {$[-15.1 ;-7.7]$} & $p<.0001$ \\
\hline & Side effects related to body modification & -4.9 & {$[-7.9 ;-1.8]$} & $p<0.0016$ \\
\hline
\end{tabular}

Health Surveillance made it a priority to conduct specific actions for professional reintegration, related to their plan to improve the quality of life of chronic disease patients.

In accordance with other studies, comorbidities like a BMI over 30, the presence of diabetes, the duration of dialysis and the smoking status reduced the quality of life in almost all dimensions, but intercurrent events of health also have a negative influence on the HRQOL in all dimensions [46-48]. Among intercurrents events, having been hospitalized in the last 4 weeks, having an infectious disease and a critical illness in the last 4 weeks, and having a recent surgery on the graft are associated with a lower HRQOL. 


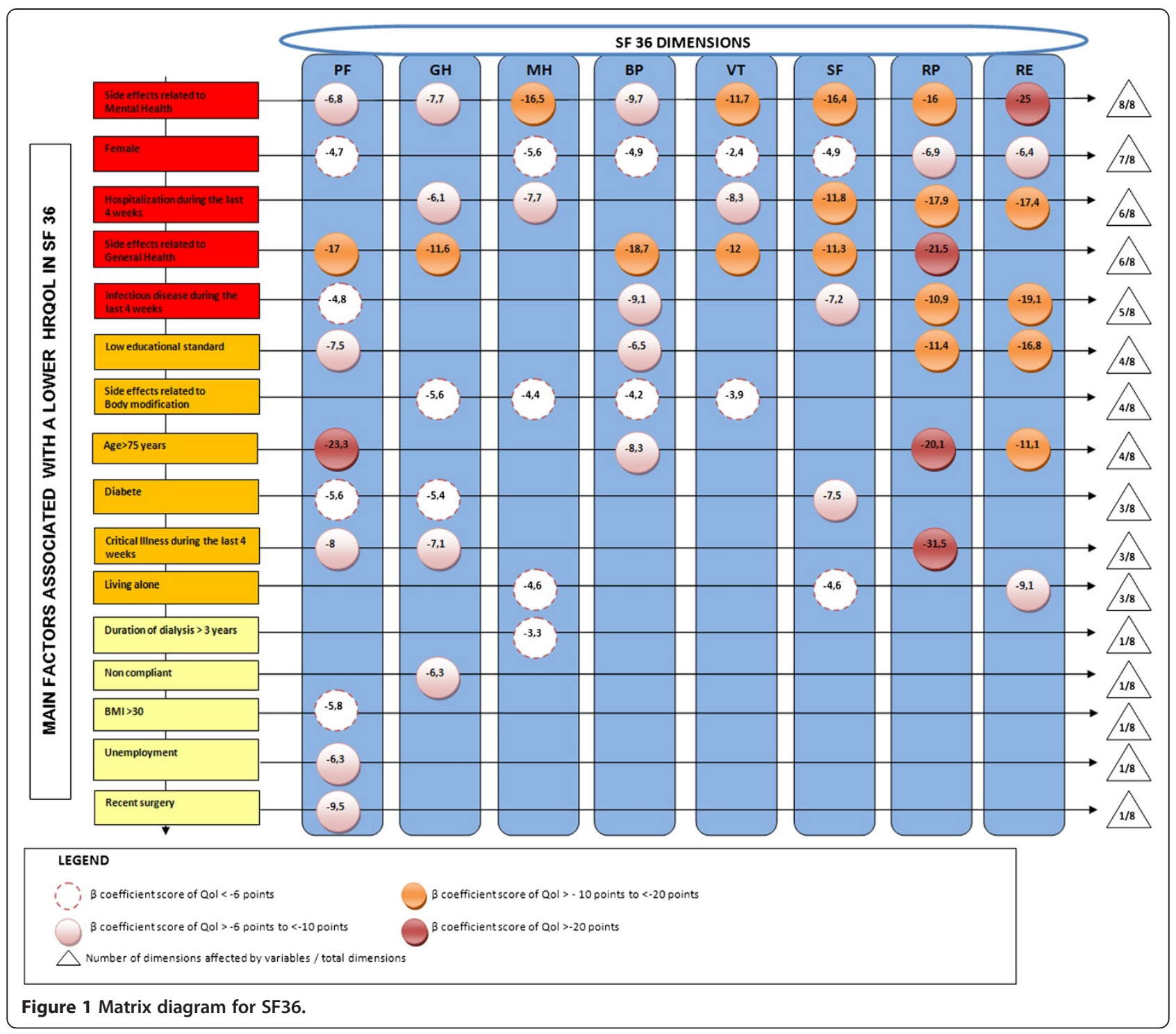

Our results also emphasized the negative impact of treatment $[49,50]$. We found that compliance and side effects were associated with very low scores [51], in every dimension and regardless of the measurement instrument used [52-54]. These results could be explained by the lack of information received concerning possible side effects, and the extreme importance of the treatment schedule [55]. Perhaps the duration of doctor's visits could be longer or more frequent, with specific health education about treatment including how the drugs must be taken and adhered to, treatment benefits, and side effects. Then, medical staff could propose specific programs to patients to handle the difficulties due to specific treatment, using a medical booklet regarding their treatment [56]. Thus, the French Biomedicine Agency and the National Health Institute for Public Health Surveillance have recommended a program for specific health education of RTR [57].
Concerning ReTransQol specific dimensions, the physical aspects of HRQOL of RTR have been reported as impaired. Physical restrictions are mostly associated with the frequent occurrence of comorbidities and side effects of immunosuppressive therapy $[58,59]$. However, we can observe that the ReTransQol specifically showed that medical variables are responsible for worsening health, especially the 3 main factors which are exclusively treatment side effects. Our study pointed out that older age has a positive influence on the fear of losing the graft dimension ( $\beta$ coeff. $=-10$ points for age $<75$ years). Indeed, elderly patients were less anxious about the fear of losing their graft.

We can consider that the ReTransQol is more sensitive than SF-36 for health status variables, but less exhaustive for socio-demographic factors. Finally, it could be very interesting to work with both, because these 


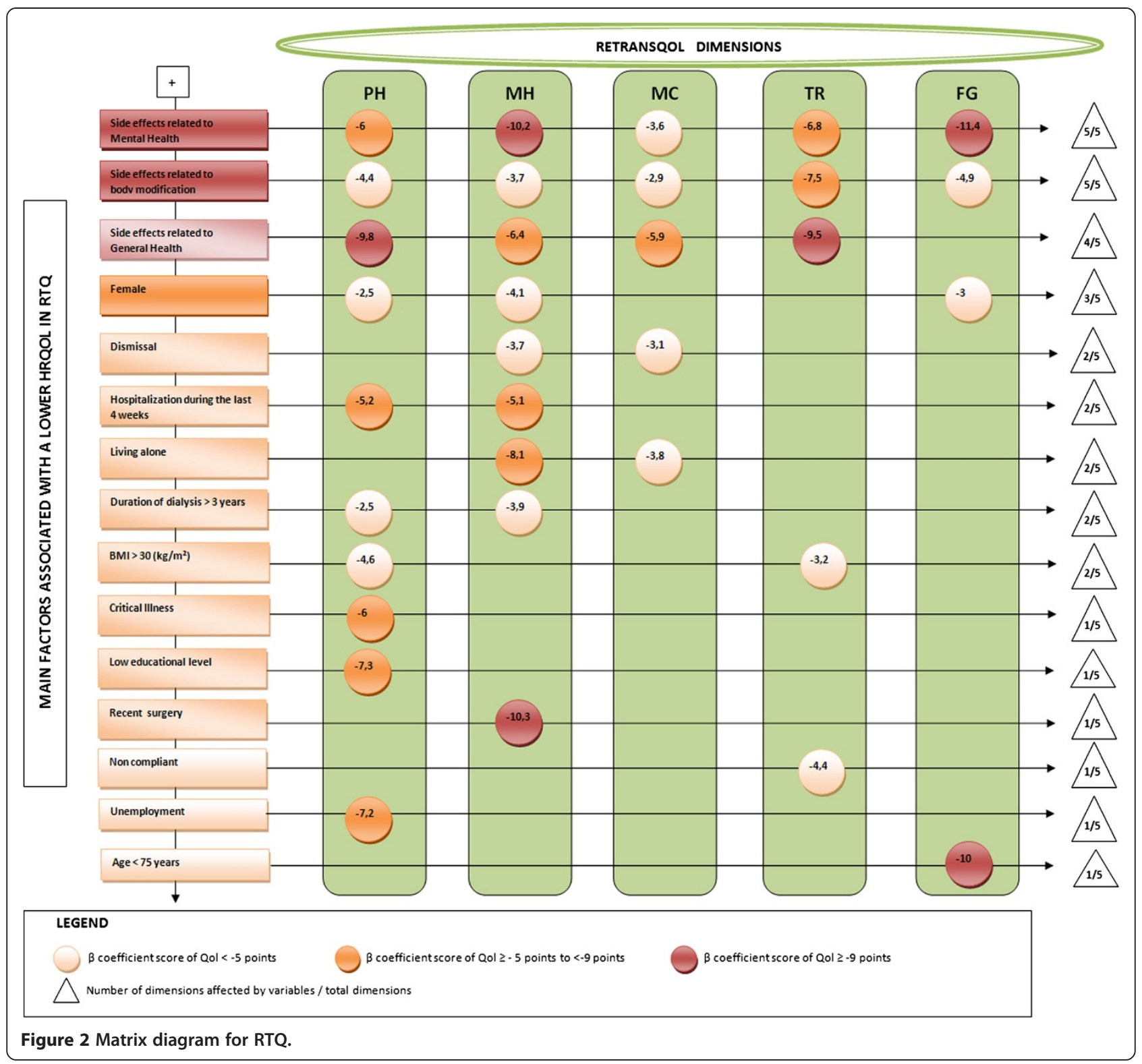

tools are complementary and offer different views on HRQOL for RTR [60]. Limitations of our research are related to the study design (cross-sectional), so we cannot truly interpret predictive factors. A cohort study or panel study would allow us to analyze risk factors and use correlations to determine absolute predictive factors. However, this study is currently repeated under the same conditions to compare scores and its evolution over time.

\section{Conclusion}

The clinical relevance of this study lies in demonstrating that comorbidities frequently occur as side effects of immunosuppressive therapy, such as hypertension and diabetes, which are associated with physical aspects of the
HRQOL after renal transplantation. Therefore, the occurrence of these side effects should be taken into account in the choice of the renal replacement therapy (dialysis or transplantation). In addition, it is possible that public policies directed toward vocational rehabilitation may lead to positive effects in mental HRQOL. Intervention to improve mental HRQOL on personal factors indirectly related to health may increase the probability of professional rehabilitation, with personal as well as socioeconomic advantages. A better understanding of the role of personal factors is essential in the development of psychosocial interventions to maximize HRQOL. Given that treatment side effects negatively impact every level of HRQOL, we recommend a better medical follow-up of side effects, considering specificities 
related to gender. Having a professional activity seems to be a major element in improving the HRQOL of RTR. These actions are integrated into the national HRQOL improvement plan in France. Repetition of this study is necessary to measure the impact of actions, and is now underway with a larger sample including more than 20 regions in France.

\section{Summary}

This study aims to identify factors associated with health related quality of life (HRQOL) through a comprehensive analysis of sociodemographic and clinical variables among a representative sample size of renal transplant recipients in France.

\section{Consent}

"Written informed consent was obtained from the patient for publication of this report and any accompanying images".

\section{Competing interests}

The authors declare that they have no competing interests.

\section{Authors' contributions}

SG conceived the study and its design, coordinated the data management, analyzed and interpreted the data, drafted the manuscript; DB performed some statistical analysis, analyzed and interpreted the data and drafted the manuscript; ES participated to the interpretation of data and revised the manuscript. EJ participated in the design of the study, collected the data and performed the statistical analysis BD participated in the design of the study, collected medical data and participated to the interpretation of data CJ et SB revised the manuscript critically for important intellectual content and have given final approval of the version to be published. All authors read and approved the final manuscript.

\section{Acknowledgements}

The authors would like to thank patients, the FNAIR association, nephrologists and clinical technician for their participation. The study was supported by a grant from the Biomedicine Agency, the Health National Institute for Public Health Surveillance (InVS), the ARS PACA (Agence Régionale de Santé) and the ADEREM (Association pour le développement des recherches biologiques et médicales).

All members of « qualité de vie du réseau REIN » group : Ben Saïd M., de Peretti C., Daurès JP, Duny Y., Loos Ayav C., Mercier S., Sambuc R., Dussol B., Durand AC.

\section{Author details \\ 'Laboratoire de Santé Publique, Faculté de Médecine, Université Aix-Marseille, Marseille EA 3279, France. ${ }^{2}$ Service Santé Publique et Information Médicale, CHU Marseille, Marseille, France. ${ }^{3}$ Centre de Néphrologie et de Transplantation Rénale, CHU Marseille, Marseille, France. ${ }^{4}$ Agence de la Biomédecine, Paris, France. ${ }^{5}$ Epidémiologie et Evaluation Cliniques, CHU Nancy, Nancy, France. ${ }^{6}$ Université de Lorraine, Université Paris Descartes, Apemac, Nancy EA 4360, France.}

Received: 2 November 2012 Accepted: 15 May 2013 Published: 30 May 2013

\section{References}

1. Stewart AL, Hays RD, Ware JE: Methods of validating MOS health Measures. In Measuring functioning and well-being: the medical outcomes study approach. Edited by Stewart AL, Ware JE. Durham, NC: Duke University Press; 1992:309-324.

2. Jay $C L$, Butt Z, Ladner DP, Skaro Al, Abecassis MM: A review of quality of life instruments used in liver transplantation. J Hepatol 2009, 51(5):949-959.
3. Ortega T, Deulofeu R, Salamero P, Roman A, Masnou N, Rubio S, et al: Health-related quality of life before and after a solid organ transplantation (kidney, liver, and lung) of four Catalonia hospitals. Transplant Proc 2009, 41(6):2265-2267.

4. Fujisawa M, Ichikawa Y, Yoshiya K, Isotani S, Higuchi A, Nagano S, et al: Assessment of health-related quality of life in renal transplant and hemodialysis patients using the SF-36 health survey. Urology 2000, 56(2):201-206.

5. Maglakelidze N, Pantsulaia T, Tchokhonelidze I, Managadze L, Chkhotua A: Assessment of health-related quality of life in renal transplant recipients and dialysis patients. Transplant Proc 2011, 43(1):376-379.

6. Jofré R, López-Gómez JM, Moreno F, Sanz-Guajardo D, Valderrábano F: Changes in quality of life after renal transplantation. Am J Kidney Dis 1998, 32(1):93-100.

7. Rebollo P, Ortega F, Baltar JM, Badía X, Alvarez-Ude F, Díaz-Corte C, et al: Health related quality of life (HRQOL) of kidney transplanted patients: variables that influence it. Clin Transplant 2000, 14(3):199-207.

8. Tonelli M, Wiebe N, Knoll G, Bello A, Browne S, Jadhav D, et al: Systematic review: kidney transplantation compared with dialysis in clinically relevant outcomes. Am J Transplant 2011, 11(10):2093-2109.

9. Dew MA, Switzer GE, Goycoolea JM, Allen AS, DiMartini A, Kormos RL, et al: Does transplantation produce quality of life benefits? A quantitative analysis of the literature. Transplantation 1997, 64(9):1261-1273.

10. Landreneau K, Lee K, Landreneau MD: Quality of life in patients undergoing hemodialysis and renal transplantation-a meta-analytic review. Nephrol Nurs J 2010, 37(1):37-44.

11. Alavi NM, Aliakbarzadeh Z, Sharifi K: Depression, anxiety, activities of daily living, and quality of life scores in patients undergoing renal replacement therapies. Transplant Proc 2009, 41(9):3693-3696.

12. Baguelin-Pinaud A, Moinier D, Fouldrin G, Le Roy F, Etienne I, Godin M, et al: [Renal transplantation, anxiety and depressive disorders and quality of life]. Encéphale 2009, 35(5):429-435.

13. Tavallaii SA, Einollahi B, Azizabadi Farahani M, Namdari M: Socioeconomic links to health-related quality of life, anxiety, and depression in kidney transplant recipients. Iran J Kidney Dis 2009, 3(1):40-44.

14. Prihodova L, Nagyova I, Rosenberger J, Roland R, van Dijk JP, Groothoff JW: Impact of personality and psychological distress on health-related quality of life in kidney transplant recipients. Transpl Int 2010, 23(5):484-492.

15. Kovacs AZ, Molnar MZ, Szeifert L, Ambrus C, Molnar-Varga M, Szentkiralyi A, et al: Sleep disorders, depressive symptoms and health-related quality of life-a cross-sectional comparison between kidney transplant recipients and waitlisted patients on maintenance dialysis. Nephrol Dial Transplant 2011, 26(3):1058-1065.

16. Pollice R, Di Mauro S, Bernardini M, Bianchini V, Giordani Paesani N, Ussorio $D$, et al: [Psychopathology, quality of life and social functioning in dialysis treatment and kidney transplantation patients]. Clin Ter 2010, 161(4):329-333.

17. OMS: Prévention des maladies chroniques: un investissement vital [Internet]. WHO. Available de: http://www.who.int/chp/chronic_disease_report/part1/ $\mathrm{fr} /$ index $16 . \mathrm{html}$.

18. LOI n²004-806 du 9 août 2004 relative à la politique de santé publique | Legifrance [Internet]. Available de: http://www.legifrance.gouv.fr/affichTexte. docidTexte $=J$ ORFTEXT000000787078\&dateTexte $=\&$ categorieLien=id.

19. Jungers P, Choukroun G, Robino C, Massy ZA, Taupin P, Labrunie M, et al: Epidemiology of end-stage renal disease in the lle-de-France area: a prospective study in 1998. Nephrol Dial Transplant 2000, 15(12):2000-2006.

20. Labeeuw M: Treatment of end stage renal failure by dialysis in RhôneAlpes: changes over the period 1993-1999. Nephrologie 2001, 22(4):161-166.

21. Couchoud C, Stengel B, Landais P, Aldigier J-C, de Cornelissen F, Dabot C, et al: The renal epidemiology and information network (REIN): a new registry for end-stage renal disease in France. Nephrol Dial Transplant 2006, 21(2):411-418.

22. Strang $\mathrm{WN}$, Tuppin $\mathrm{P}$, Atinault $\mathrm{A}$, Jacquelinet $\mathrm{C}$ : The French organ transplant data system. Stud Health Technol Inform 2005, 116:77-82.

23. Boini S, Bloch J, Briançon S: [Monitoring the quality of life of end-stage renal disease patients. Quality of life report - REIN - Dialysis 2005]. Nephrol Ther 2009, 5(Suppl 3):S177-S237.

24. WHO: The anatomical therapeutic chemical classification system with defined daily doses (ATC/DDD) [internet]. WHO. [cité 2012 avr 19]. Available de: http:// www.who.int/classifications/atcddd/en/. 
25. Rosenberger J, van Dijk JP, Nagyova I, Zezula I, Geckova AM, Roland R, et al: Predictors of perceived health status in patients after kidney transplantation. Transplantation 2006, 81(9):1306-1310

26. Leplège A, Coste J: Introduction, enjeux, définitions. Mesure de la santé perceptuelle et de la qualité de vie: méthodes et applications. In Edited by Estem.; 2002:15-36.

27. Gentile S, Jouve E, Dussol B, Moal V, Berland Y, Sambuc R: Development and validation of a French patient-based health-related quality of life instrument in kidney transplant: the ReTransQoL. Health Qual Life Outcomes 2008, 1:78.

28. Ponton P, Rupolo GP, Marchini F, Feltrin A, Perin N, Mazzoldi MA, et al: Quality-of-life change after kidney transplantation. Transplant Proc 2001, 33(1-2):1887-1889.

29. Ogutmen B, Yildirim A, Sever MS, Bozfakioglu S, Ataman R, Erek E, et al: Health-related quality of life after kidney transplantation in comparison intermittent hemodialysis, peritoneal dialysis, and normal controls. Transplant Proc 2006, 38(2):419-421.

30. Rambod M, Shabani M, Shokrpour N, Rafii F, Mohammadalliha J: Quality of life of hemodialysis and renal transplantation patients. Health Care Manag (Frederick) 2011, 30(1):23-28.

31. Humar A, Denny R, Matas AJ, Najarian JS: Graft and quality of life outcomes in older recipients of a kidney transplant. Exp Clin Transplant 2003, 1(2):69-72

32. Matas AJ, McHugh L, Payne WD, Wrenshall LE, Dunn DL, Gruessner RW: Long-term quality of life after kidney and simultaneous pancreas-kidney transplantation. Clin Transplant 1998, 12(3):233-242.

33. Bohlke M, Marini SS, Rocha M, Terhorst L, Gomes RH, Barcellos FC, et al: Factors associated with health-related quality of life after successful kidney transplantation: a population-based study. Qual Life Res 2009, 18(9):1185-1193.

34. Fiebiger W, Mitterbauer C, Oberbauer R: Health-related quality of life outcomes after kidney transplantation. Health Qual Life Outcomes 2004, 2:2.

35. Stavem K, Ganss R: Reliability and validity of the ESRD symptom checklist-transplantation module in Norwegian kidney transplant recipients. BMC Nephrol 2006, 7:17.

36. Molnar-Varga M, Molnar MZ, Szeifert L, Kovacs AZ, Kelemen A, Becze A, et al: Health-related quality of life and clinical outcomes in kidney transplant recipients. Am J Kidney Dis 2011, 58(3):444-452.

37. Unruh ML, Weisbord SD, Kimmel PL: Health-related quality of life in nephrology research and clinical practice. Semin Dial 2005, 18(2):82-90.

38. Ortega F, Valdés C, Ortega T: Quality of life after solid organ transplantation. Transplant Rev 2007, 21(3):155-170.

39. Wight JP, Edwards L, Brazier J, Walters S, Payne JN, Brown CB: The SF36 as an outcome measure of services for end stage renal failure. Qual Health Care 1998, 209(4):209-221.

40. Ichikawa Y, Fujisawa M, Hirose E, Kageyama T, Miyamoto Y, Sakai Y, et al: Quality of life in kidney transplant patients. Transplant Proc 2000, 32(7):1815-1816.

41. Rebollo P, Ortega F, Baltar JM, Díaz-Corte C, Navascués RA, Naves M, et al: Health-related quality of life (HRQOL) in end stage renal disease (ESRD) patients over 65 years. Geriatr Nephrol Urol 1998, 8(2):85-94.

42. Kontodimopoulos N, Pappa E, Niakas D: Gender- and age-related benefit of renal replacement therapy on health-related quality of life. Scand J Caring Sci 2009, 23:721-729.

43. Van der Mei SF, Groothoff JW, van Sonderen ELP, van den Heuvel WJA, de Jong $P E$, van Son WJ: Clinical factors influencing participation in society after successful kidney transplantation. Transplantation 2006, 82(1):80-85.

44. Fructuoso M, Castro R, Oliveira L, Prata C, Morgado T: Quality of life in chronic kidney disease. Nefrologia 2011, 31(1):91-96.

45. White $C$, Gallagher P: Effect of patient coping preferences on quality of life following renal transplantation. J Adv Nurs 2010, 66(11):2550-2559.

46. Rosenberger J, van Dijk JP, Nagyova I, Roland R, Geckova AM, van den Heuvel WJA, et al: Do dialysis- and transplantation-related medical factors affect perceived health status? Nephrol Dial Transplant 2005, 20(10):2153-2158

47. Siegal B, Halbert RJ, McGuire MJ: Life satisfaction among kidney transplant recipients: demographic and biological factors. Prog Transplant 2002, 12(4):293-298.

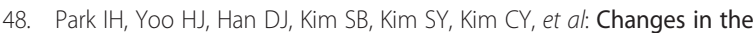
quality of life before and after renal transplantation and comparison of the quality of life between kidney transplant recipients, dialysis patients, and normal controls. Transplant Proc 1996, 28(3):1937-1938.
49. Calia R, Lai C, Aceto P, Luciani M, Romagnoli J, Lai S, et al: Effects of switching from twice-daily to once-daily tacrolimus formulation on quality of life, anxiety, and transplant benefit perception after kidney transplantation. Transplant Proc 2011, 43(4):1020-1023.

50. Prasad GVR, Nash MM, Keough-Ryan T, Shapiro RJ: A quality of life comparison in cyclosporine- and tacrolimus-treated renal transplant recipients across Canada. J Nephrol 2010, 23(3):274-281.

51. Kim HS, So HS: [A prediction model development on quality of life in kidney transplant recipients]. J Korean Acad Nurs 2009, 39(4):518-527.

52. Hilbrands LB, Hoitsma AJ, Koene RA: Medication compliance after renal transplantation. Transplantation 1995, 60(9):914-920.

53. Kiley DJ, Lam CS, Pollak R: A study of treatment compliance following kidney transplantation. Transplantation 1993, 55(1):51-56.

54. De Geest S, Borgermans L, Gemoets H, Abraham I, Vlaminck H, Evers G, et al: Incidence, determinants, and consequences of subclinical noncompliance with immunosuppressive therapy in renal transplant recipients. Transplantation 1995, 59(3):340-347.

55. Al-Aradi A, Phelan PJ, O'Kelly P, Khan AH, Rahman MA, Hanley A, et al: An assessment of the long-term health outcome of renal transplant recipients in Ireland. Ir J Med Sci 2009, 178(4):407-412.

56. Wilkins F, Bozik K, Bennett K: The impact of patient education and psychosocial supports on return to normalcy 36 months post-kidney transplant. Clin Transplant 2003, 17:78-80.

57. Grenier B, Bourdillon F, Gagnayre R: Le développement de l'éducation thérapeutique en France: politiques publiques et offres de soins actuelles. Sante Publique 2007, 19(4):283.

58. Rosenberger J, Geckova AM, Dijk JP, Roland R, Heuvel WJ, Groothof FJW: Factors modifying stress from adverse effects of immunosuppressive medication in kidney transplant recipients. Clin Transplant 2005, 19(1):70-76.

59. Oppenheimer F, Rebollo P, Grinyo JM, Ortega F, Sanchez-Plumed J, Gonzalez-Molina M, et al: Health-related quality of life of patients receiving low-toxicity immunosuppressive regimens: a substudy of the symphony study. Transplantation 2009, 87(8):1210-1213.

60. Gentile S, Delarozière JC, Fernandez C, Tardieu S, Devictor B, Dussol B, et at Review of quality of life instruments used in end-stage renal disease. Nephrologie 2003, 24(6):293-301.

doi:10.1186/1477-7525-11-88

Cite this article as: Gentile et al:: Factors associated with health-related quality of life in renal transplant recipients: results of a national survey in France. Health and Quality of Life Outcomes 2013 11:88.

\section{Submit your next manuscript to BioMed Central and take full advantage of:}

- Convenient online submission

- Thorough peer review

- No space constraints or color figure charges

- Immediate publication on acceptance

- Inclusion in PubMed, CAS, Scopus and Google Scholar

- Research which is freely available for redistribution 